\title{
LA REGULACIÓN CONTENIDA EN LA LEY 19.496 SOBRE PROTECCIÓN DE LOS DERECHOS DE LOS CONSUMIDORES Y LAS REGLAS DEL CÓDIGO CIVIL Y COMERCIAL SOBRE CONTRATOS: UN MARCO COMPARATIVO
}

\section{THE CHILEAN CONSUMER STATUTE (N 19.496) AND THE RULES OF CIVIL AND COMMERCIAL CODES ON CONTRACTS: A FRAME COMPARISON}

\author{
Jorge Baraona GonZÁlez*
}

\begin{abstract}
RESUMEN: El presente artículo realiza un cuadro comparativo entre la Ley del Consumidor en Chile, No 19.496, con las instituciones clásicas del Derecho Privado (Códigos Civil y de Comercio chilenos) en tres áreas: la formación del consentimiento, los efectos de las obligaciones y la responsabilidad. Llegamos a la conclusión de que existe una especificidad que debe ser respetada, en el esfuerzo por integrar ambos sistemas, respetando las particularidades de ambos.
\end{abstract}

Palabras clave: Consumidor, transparencia, cláusulas abusivas, responsabilidad.

ABSTRACT: The present study examines a comparative frame between the Chilean Consumer Statue, No. 19,496, with classical institutions of private law (Chilean Civil and Commercial Codes) in three areas: formation of consent, effects of obligations, and liability. We conclude that there is a specificity that must be respected, in the effort for integrate both systems, respecting the peculiarities of both systems.

Key words: Consumer, transparency, abusive clauses, liability.

\section{INTRODUCCIÓN}

El presente trabajo tiene por finalidad estudiar, en un esquema comparativo, los actos sujetos a la Ley 19.496 y los que se someten al derecho civil o comercial, es decir, a la legislación común ${ }^{1}$ en tres aspectos centrales: a) formación del consentimiento, b) libertad de contratación y c) responsabilidad civil. Se asume que la Ley de protección de los derechos de los consumidores establece ciertas peculiaridades ${ }^{2}$ que suponen una modificación

\footnotetext{
* Doctor en Derecho. Profesor de Derecho Civil, Universidad de los Andes, correo electrónico: jbaraona@ andes.cl.

1 El estudio que suscitó mi interés por estos temas fue de CAPrile (2008).

2 Corral (2011) pp. 13-17: por ejemplo, da cuenta de las insuficiencias del sistema de responsabilidad civil común, para configurar la responsabilidad por productos defectuosos o inseguros, que es una parte, aunque mal regulada, de la Ley de protección de los derechos de los consumidores.
} 
a los principios y reglas generales del derecho civil y comercial ${ }^{3}$ respecto de estos aspectos ${ }^{4}$. Estoy bien consciente que para nadie es un misterio que existen diferencias, pero me parece que ellas no se han presentado en nuestro país de una manera general, como este estudio lo hace, con el fin de determinar con mayor precisión uno y otro sistema, de cara a configurar la manera en que el derecho común encaja en la Ley 19.496, como conjunto normativo supletorio. Más aún, el estudio tiene interés en razón de la amplia posibilidad de expandir la aplicación de la Ley 19.496, tanto así que se oyen voces que sostienen que ya el Código Civil no es el derecho común o ley general ${ }^{5}$, lo que justifica un estudio que destaque de una manera comprensiva las diferencias entre ambos sistemas para los temas indicados, con el fin de encontrar las vías de integración entre ambos regímenes, respetando las peculiaridades de la normativa sobre protección de los consumidores. Es más, hay áreas, como la regulación de los contratos de adhesión y de cláusulas abusivas, por ejemplo, que tendrán innegable influencia en el campo del derecho común.

En fin, digamos que este trabajo se propone abrir un campo de investigación que analice temas contractuales en que ambos sistemas coincidan, fijando sus respectivas peculiaridades. Se constata que todavía existe un anclaje exagerado en los principios tradicionales, que hace compleja la operación de la Ley 19.496.

\footnotetext{
3 Sото (2004) p. 187: "El progreso económico y el desarrollo tecnológico han originado una alteración de las estructuras sociales, un cambio social. En este contexto, la contratación privada, basada en un sistema de intercambios paritario, ha cedido ante la exigencia de la sociedad por acceder al mercado en forma masiva, lo que a su vez ha generado el nacimiento de un nuevo sistema de contratación: la contratación masiva”.

4 Las materias que tradicionalmente se regulan en estas leyes de protección al consumidor, buscan consagrar la libertad de escoger y decidir de los consumidores y proteger su legítima expectativa en el consumo de bienes y servicios, exigiendo plena transparencia a los proveedores y evitando todo tipo de fraudes y engaños y demandándoles plena seguridad respecto de los bienes y servicios que ofrezcan, estatuyendo vías efectivas para la protección de sus derechos. Cfr. Micklitz, Reich y Rott, (2009) p. 6.

5 Cfr. Momberg (2012) pp. 377-391: quien postula la tesis de que la Ley 19.496 hoy debe considerarse como derecho común, por su amplia aplicación en las relaciones de las PYMES con sus proveedores, lo que lleva al autor a sugerir a una reforma: "Si entendemos que el Código Civil debe ser el derecho común o ley general del sistema de derecho privado, su normativa debe incluir la regulación general de aquellos contratos en que una de las partes se encuentre en una situación de desventaja o vulnerabilidad frente a otra. Ello incluye no solo a los consumidores sino que también a quienes se encuentren, en el caso particular, en una situación asimilable", Momberg (2012) p. 391. La Ley 20.416, que FIJA NORMAS ESPECIALES PARA LAS EMPRESAS DE MENOR TAMAÑO, dispone: "Para los efectos de esta ley se entenderá por proveedores las personas naturales o jurídicas que, definidas de acuerdo con el artículo $1^{\circ}$ de la ley $\mathrm{N}^{\circ} 19.496$, desarrollen las actividades allí señaladas respecto de micro y pequeñas empresas". Y en materia de normas aplicables a los actos y contratos celebrados entre micro o pequeñas empresas y sus proveedores, refiere los párrafos $1^{\circ}, 3^{\circ}, 4^{\circ}$ y $5^{\circ}$ del Título II, y en los párrafos $1^{\circ}, 2^{\circ}, 3^{\circ}$ y $4^{\circ}$ del Título III o, a opción de las primeras, las demás disposiciones aplicables entre partes, de dicha Ley. En ningún caso serán aplicables las normas relativas al rol del Servicio Nacional del Consumidor. La aplicación de las disposiciones señaladas precedentemente será irrenunciable anticipadamente por parte de las micro y pequeñas empresas. Para un comentario actualizado de la implicancia de esta Ley en esta materia, Momberg (2013b) p. 14-16.
} 


\section{LA FORMACIÓN DEL CONSENTIMIENTO EN LA LEY DE PROTECCIÓN DE LOS DERECHOS DE LOS CONSUMIDORES}

\subsection{La autonomía privada en el Código Civil y Comercial}

Como se sabe, el derecho de los contratos, tanto civiles como comerciales, descansa en la idea de la libertad contractual, en su doble dimensión, libertad de contratación, es decir, libertad para celebrar un contrato que incluye la facultad de escoger con quién hacerlo y la libertad de configuración interna y de modificación del mismo, entendida como la autonomía que las partes tienen para determinar el contenido del contrato celebrado, en la medida que no se pacten cláusulas contrarias a la ley, a las buenas costumbres o al orden público $^{6}$. El Código Civil establece en el artículo 1445, como regla suprema, para que alguien pueda quedar obligado a otro por un acto o declaración de voluntad, es necesario que se consienta en dicho acto o declaración y que tal consentimiento no adolezca de vicios (aparte del objeto, la causa y la capacidad).

Aunque el Código Civil no regula la formación del consentimiento, sin embargo establece reglas sobre eventuales vicios que pueden adolecer, a fin de asegurar la libertad de contratación, tanto respecto con quien se contrata, como del contrato mismo que se celebra, y de su objeto. Son atentados graves a la libertad de contratar, el dolo y la fuerza, que la ley los califica como vicios del consentimiento. Paralelamente, y como una manera de llenar un vacío que se apreciaba en el Código Civil, el Código de Comercio dispuso reglas sobre formación del consentimiento, que se entiende que son también aplicables a los contratos civiles (artículos 97 a 106) ${ }^{7}$. Todo este conjunto de normas permite afirmar el principio de la autonomía de la voluntad o autonomía privada, tan caro al derecho de la contratación.

La clave en los contratos civiles es la voluntad negocial o consentimiento, y ello se advierte no solo en lo que dispone el artículo 1445 del Código Civil, sino también en la norma contenida en el artículo 1545 del mismo Código, por la cual todo contrato legalmente celebrado es una ley para los contratantes y no puede ser invalidado sino por consentimiento mutuo o por causas legales, consagrándose el tradicional principio del pacta sunt servanda. En materia de interpretación contractual, la doctrina jurisprudencial y de los autores ha encontrado en el artículo 1560 del Código Civil una regla que también descansa en el principio de autonomía de la voluntad, cuando ordena, como primera regla interpretativa, aplicar la intención de los contratantes, si ella es claramente conocida, respecto de la letra del mismo contrato. Esto significa que la voluntad contractual (la intención única de los contratantes) es un elemento que no solo da vida al contrato, sino que, además, orienta su ejecución, hasta el total cumplimiento del mismo ${ }^{8}$.

La libertad contractual se apoya en el supuesto de que las personas son libres e iguales, y por lo tanto, protegiéndose esa libertad e igualdad consustancial a todo ser humano, el resultado de toda negociación contractual debe ser bienvenido. Para asegurar esa libertad de negociación el Código Civil pone el acento en la libertad de consentir y, por lo mismo,

\footnotetext{
6 Véase Barcia (2006); y de una manera más general, véase López Santa María (2010) pp. 191-221.

7 Sobre formación del consentimiento en el derecho común, véase SaAVEDRA (1994) passim.

8 Sobre este tema en Chile, véase López Santa María (2010) pp. 387-413.
} 
asegura a las partes la posibilidad de pedir la nulidad del acto, cuando su consentimiento aparece afectado por error, por fuerza o por dolo.

En cuanto a los deberes de información en las tratativas preliminares, no existe un principio general en derecho civil y comercial que obligue a los que negocian un contrato a ser plenamente transparentes ${ }^{9}$, es decir, a dar plena información sobre lo que se negocia, aunque con el tiempo se han ido perfilando deberes de informar previos a la celebración del contrato $^{10}$, basados en el principio de la buena fe contractual, apoyados en el artículo 1546 del Código Civil, tema que está en pleno desarrollo dogmático y jurisprudencial ${ }^{11}$.

Si a lo anterior agregamos el reforzamiento que la propia Constitución chilena establece a la libertad de contratación, al asegurar y garantizar como derecho constitucional, que todas las personas son libres para desarrollar cualquier actividad económica (cfr. artículo $19 \mathrm{n}^{\circ} 21$ ), lo que supone la libertad de asociación empresarial y de negociación contractual, quiere decir que en nuestro sistema civil y comercial, la autonomía de la voluntad es un principio fundamental ${ }^{12}$.

\subsection{LA PROTECCIÓN DE LOS DERECHOS DE LOS CONSUMIDORES Y LA AUTONOMÍA PRIVADA}

\section{a) El principio de la transparencia}

Si revisamos ahora las reglas de la Ley 19.496, podemos advertir que el paradigma de la autonomía privada no encaja con la misma profundidad en los actos de consumo ${ }^{13}$.

\footnotetext{
9 De la Maza (2010) pp. 25: "la idea que pretendo defender es que, si bien puede aceptarse que los deberes precontractuales de informar constituyen manifestaciones de las exigencias que impone la buena fe a las partes durante la negociación del contrato, es erróneo afirmar que la buena fe impone siempre, o al menos, en términos extremadamente amplios a las partes el deber de suministrarse recíprocamente información mientras negocian un contrato".

10 Zuluoaga Ríos (2005); Barrientos Zamorano (2008).

11 Sobre tema, véase De la MAZA (2008); Barros (2006) pp. 1125-1126, tiene dicho a este respecto: a) En contraste extremo con los contratos masivos, es convenientes referirse a la lógica diferencia que tienen los contratos de libre discusión. Aunque excepcionales en número, suelen ser económicamente los más significativos (lo que justifica el costo de negociar). Por cierto que en estos casos se aplican las reglas generales, en cuya virtud la información maliciosamente falsa da lugar a la responsabilidad. La práctica contractual hace que en estos casos cada parte exija de la otra las declaraciones contractuales formales acerca de los aspectos del negocio que resultan esenciales. De este modo, la información forma parte del acuerdo contractual mismo, porque cada parte ha negociado con la otra cuál información debe proporcionarle y las garantías de verdad respecto de los hechos que son de dominio de la contraparte y que estima esenciales para dar el consentimiento. Por lo mismo, el incumplimiento de las declaraciones y garantías da lugar a responsabilidad contractual, en los términos que hayan convenido o, supletoriamente, según el derecho común. b) En definitiva, los extremos de los contratos negociados por empresarios con asesoría profesional y los contratos masivos muestran que los deberes de información, como en general, los que derivan de la buena fe, son tanto más intensos cuanto menores son las posibilidades reales que tienen las partes de cautelar sus propios intereses durante la negociación (de modo que mayor es la confianza que deben poner en la contraparte". Por su parte Boestch Gillet (2011) p. 141: precisa, "Cabe apuntar que el deber de información que impone la buena fe no significa que cada parte deba "desnudarse", en el sentido de entregarle información confidencial que no sería necesaria conocer para el contrato en particular que se pretende celebrar. Por ello, repetimos que la información debe ser suficiente, completa y exacta”.

12 Cfr. Fermandois (2001) p. 91.

13 Wahl (2006) p. 77: "La realidad y regulación por adhesión es difícilmente conciliable con los postulados del dogma de la voluntad, sobre los que se ha construido la teoría del contrato en el derecho Continental. Lo
} 
El supuesto de fondo que se suele invocar para explicar la estricta regulación de los actos sujetos a la ley del consumidor, dicen relación con un desequilibrio que se advierte entre proveedores de bienes y servicios y los consumidores, en términos de una fuerza económica superior o muy superior, dependiendo de los casos, de una falta de equilibrio o asimetría en materia de información ${ }^{14}$ y de la necesidad de evitar, por lo mismo, abusos en contra de los consumidores $^{15}$. Más al fondo de la cuestión, aparece un tema de orden público ${ }^{16}$ económico ${ }^{17}$, por el cual se postula que el desarrollo de la economía y del consumo exige ofrecer confianza a los consumidores ${ }^{18}$, en donde al proveedor no solo se le exige transparencia en la oferta sino en general lealtad en el cumplimiento de buenas prácticas comerciales ${ }^{19}$, la buena fe llega entonces a exigir una operación comercial respetuosa de los consumidores. No se trata ya de proteger la pura libertad contractual, en el sentido de asegurar libertad a la espontánea decisión de contratar, sino de garantizar a los consumidores que los bienes y servicios que se les ofrecen podrán adquirirlos, o servirse de ellos, en los términos que ellos

anterior es evidente, si contrastamos los principios que inspiran las normas clásicas sobre formación del consentimiento, especialmente la idea de una total y consciente concordancia entre una oferta y aceptación, y la forma en que los contratos de adhesión obtienen en la práctica su fuerza obligatoria. Pareciera entonces que la dimensión del contrato como relación jurídica privada de intercambio más que un acuerdo de voluntades, cobra en este caso una relevancia que impone matizar las consecuencias del dogma de la voluntad".

14 De la MaZa (2010a) p. 113: para justificar deberes de información impuesto por la ley, y más allá del deber de buena fe, "existen ciertas relaciones que se caracterizan por una cierta desigualdad entre las partes. Lo que deseo agregar ahora es que esas desigualdades, generalmente -y en lo que interesa a este trabajo- se explican como un problema de asimetrías informativas, es decir, por las ventajas que, en términos de información, posee una de las partes sobre la otra”.

15 Lorenzetti (2004) p. 138: "La noción de consumidor se relaciona con un hecho jurídico, que es el 'consumir', y no específicamente con la calidad de acreedor o deudor de una obligación o con un contrato en particular. Permite ser aplicada a una cantidad de contratos disímiles. Toma en cuenta específicamente la posición de debilidad estructural en el mercado. En los casos anteriores, se tomaba en cuenta una falla coyuntural del mercado, la situación en la cual un deudor es débil por circunstancias del caso. En cambio ahora se pretende tomar en cuenta una posición permanente, porque es estructural: se relaciona con la conformación asimétrica de las relaciones de mercado, en las que la ideación, producción, y difusión de la existencia de bienes se concentra progresivamente, mientras que el consumo se dispersa”. Explican Werner y NeHME (2005) p. 661: "El derecho contractual clásico entrega herramientas para controlar los abusos de poder en estas circunstancias, a pesar de su predominante carácter formalista. Esto supone aceptar un alejamiento de la 'situación contractual perfecta' e interpretar las conductas de las partes a la luz de su coherencia con los principios de la buena fe, orden público y buenas costumbres. Un adecuado uso de estos conceptos abiertos, que integran el derecho civil con las convicciones sociales vigentes, permite determinar que la autonomía privada nunca puede ejercerse en violación de la autodeterminación de otro: ello se opone al orden civil básico que tutela el orden público y las buenas costumbres. Así es lícita la actualización de la autonomía privada que supone imponer los propios fines a la contraparte, ya sea por abuso del monopolio, de las CGC o de los conocimientos. Del mismo modo, el concepto de buena fe en su función integradora del contrato, permite establecer la ilicitud de los negocios jurídicos que atenten contra la básica reciprocidad contractual que también supone el orden civil de los contratos conmutativos".

16 Sobre el orden público de protección y la Ley 19.496, véase TAPIA (2008) p. 494-498.

17 Sobre la noción de orden público económico, véase Fermandois (2010) pp. 27-46.

18 Es una preocupación política en la Unión Europea, por ejemplo, que las leyes de protección a los consumidores de los países miembros, contribuyan a este objetivo, véase Howells y SCHUlze (2009) pp. 8-9: "Giving the consumer the right of redress against the producer who might well be trading the consumer's home state would be a very tangible measure promoting the consumer's confidence in practical acces to justice".

19 Cfr. Rodríguez Pinto (2013). 
están siendo ofrecidos, que no serán sometidos a condiciones inicuas, que se les respetarán las condiciones y modalidades ofrecidas, que no serán dañados daños o menoscabados, entre otras cosas, y en general no serán sometidos a prácticas comerciales desleales ${ }^{20}$. Por ello, parece que el bien superior ya no es asegurar la clásica libertad de contratación, sino proteger el acto de consumo masivo, a partir de la confianza que le ha suscitado la propuesta del proveedor ${ }^{21}$. El contraste, por lo mismo, no se hace entre lo que se convino y lo que se recibió, sino entre lo que se ofreció por el proveedor $^{22}$ y lo que efectivamente este entregó. Se introduce, así, un principio rector en el derecho del consumo, que es el principio de la transparencia del proveedor. Es una depuración cuya finalidad no busca dar garantía para el logro de un consentimiento libre, sino generar condiciones para un consumo libre y confiado, que no es lo mismo, en mi opinión.

El principio de la transparencia queda recogido ampliamente en la Ley 19.456. Así, el artículo $1 \mathrm{~N}^{\circ} 2$ consagra la categoría "información básica comercial”23, que debe ser entregada al consumidor; el artículo 3 b) configura en favor de los consumidores el derecho a una información veraz y oportuna sobre los bienes y servicios ofrecidos su precio, condiciones de contratación y otras características relevantes de los mismos, y el deber de informarse responsablemente de ellos"; por su parte, el artículo 12 de la ley dispone que todo proveedor de bienes o servicios "estará obligado a respetar los términos, condiciones y modalidades conforme a las cuales se hubiere ofrecido o convenido con el consumidor la en-

\footnotetext{
20 Sobre este tema para el derecho europeo, véase OrLANDo (2011).

21 Cfr. LorenzetTi (2002) pp. 38-39: "El consumidor o usuario actual podría ser considerado negligente si se aplica un estándar contractual clásico, porque las pruebas que realiza para verificar los datos suministrados antes de contratar son muy pocas y generalmente inicuas; actúa en base a un conocimiento inductivo débil. Pero no se trata de un problema de negligencia sino de una necesidad: si se tuviera que verificar razonablemente cada acto, sería imposible vivir, y los costos de transacción serían altísimos. La conducta individual tiende a simplificar, reduciendo los costos de transacción y el agotamiento psicológico que significa pretender entender cada uno de los sistemas con los cuales uno se relaciona. Un ser racionalmente orientado no podría vivir, porque debería solicitar información sobre cada sistema, conocer el mismo, y luego actuar. La regla es la disminución de la información que se obtiene para actuar, derivada de su alto costo marginal y de oportunidad; disminuye la racionalidad y aumenta la fe en los sistemas complejos, lejanos abstractos, que llega a ser casi religiosa. El acto de relacionamiento con el sistema se automatiza, se simplifica de modo tal que el sujeto que lo celebra no tiene conciencia de sus efectos jurídicos".

22 Para un análisis comparativo y crítico acerca la oferta en el Código de Comercio, en la Ley 19.496 y en la Convención sobre Compraventa Internacional de Mercaderías, VARAS y MomberG (2006).

23 "Art. 1 No 3.- 3.- Información básica comercial: los datos, instructivos, antecedentes o indicaciones que el proveedor debe suministrar obligatoriamente al público consumidor, en cumplimiento de una norma jurídica.

Tratándose de proveedores que reciban bienes en consignación para su venta, estos deberán agregar a la información básica comercial los antecedentes relativos a su situación financiera, incluidos los estados financieros cuando corresponda.

En la venta de bienes y prestación de servicios, se considerará información comercial básica, además de lo que dispongan otras normas legales o reglamentarias, la identificación del bien o servicio que se ofrece al consumidor, así como también los instructivos de uso y los términos de la garantía cuando procedan. Se exceptuarán de lo dispuesto en este inciso los bienes ofrecidos a granel.

La información comercial básica deberá ser suministrada al público por medios que aseguren un acceso claro, expedito y oportuno. Respecto de los instructivos de uso de los bienes y servicios cuyo uso normal represente un riesgo para la integridad y seguridad de las personas, será obligatoria su entrega al consumidor conjuntamente con los bienes y servicios a que acceden”.
} 
trega del bien o la prestación del servicio". Si se lee bien esta última disposición, el proveedor no solo está obligado a respetar los términos, condiciones o modalidades convenidas, sino las que "hubiere ofrecido", con lo cual es claro que la plena información pasa a ser un elemento relevante en la relación de consumo ${ }^{24}$. Es más, del artículo 12 antes transcrito se deduce que la sola propuesta de bienes y servicios obliga al proveedor, sin esperar la aceptación de sus clientes, por lo que no es el consentimiento de sus clientes el que le impone este deber, sino la oferta hecha al público ${ }^{25}$ que compromete a quien la realiza, principio que no encontramos sino por excepción en el sistema civil y comercial.

Otra norma que recoge el principio de transparencia, es el artículo 14 de la ley, por el cual se obliga al proveedor a dar cuenta al consumidor en caso de que se vendan productos con alguna deficiencia, que sean usados, o en cuya elaboración o fabricación se hayan utilizado partes o piezas usadas. Lo mismo puede decirse de los artículos 17 A, 17B, 17 C, $17 \mathrm{D}, 17 \mathrm{G}, 17 \mathrm{~J}, 17 \mathrm{~L}$, que consagran amplios deberes de información, tanto en contratos de adhesión, como en general en proveedores de servicios de crédito o de seguros. Paralelamente, en el artículo 18 se dispone que constituye infracción a las normas de la ley, el cobro de un precio superior al exhibido, informado o publicitado ${ }^{26}$.

Por último, de una manera más general, el principio de la transparencia informa los párrafos I, II y III del Título III de la Ley, por los cuales se busca asegurar la debida información del consumidor.

En fin, no creo que sea necesario más ilustración para explicitar que estos deberes de información, con la intensidad que aparecen en el sistema de protección de los consumidores, no son propios del sistema común y hacen una importante diferencia con él. Puedo concluir que, mientras en el sistema civil y comercial solo por excepción existen deberes de información expresamente reconocidos ${ }^{27}$, y otros que derivan de una manera general del

\footnotetext{
24 Para Nunes (2011) p. 621: unos de los principios en que se informe la ley brasileña, Ley $N^{\circ} 8.8078$, de 11 de septiembre de 1990, sobre Código de Defensa del Consumidor, es que rompe con el principio del pacta sunt servanda, al establecer que en materia de relaciones de consumo rige la regla de la oferta.

25 García Vicente (2009) p. 784, tiene dicho: "La tutela de la confianza del consumidor para ser el fundamento de esta regla de integración, puesto que se protegen las expectativas del consumidor sobre la naturaleza y condiciones de las prestaciones, derivadas de las afirmaciones vertidas en las declaraciones públicas. El consumidor no tiene que soportar el riesgo de decepción que padecería si solo fueran exigibles las prestaciones prometidas en el contrato y no las afirmadas a través de las declaraciones publicitarias. Este riesgo se asigna al empresario o profesional (...) y es un criterio de imputación 'objetivo' porque basta la confianza creada por el mensaje publicitario".

26 Sobre este tema es importante lo que expresa De la Maza (2009), quien distingue, para el caso de ofertas por medios electrónicos, entre ofertas puras, y ofertas sujetas a reserva, estas últimas no serían vinculantes para el predisponente o proveedor si el usuario o consumidor pudo acceder clara e inequívocamente a los términos que proponían la reserva. No comparto este criterio, porque el autor le da un valor a las cláusulas que contienen la reserva, bajo criterios que solo parecen proteger el consentimiento informado, y no la confianza en el consumo, que es el valor que se protege una vez que el consumidor ha aceptado.

27 Típicos les llama De la Maza (2010b). p. 94: "En el derecho común -que es la principal sede en que se presenta la cuestión de los deberes atípicos- la cuestión es distinta, la regulación del contrato reposa sobre las asunciones de igualdad y libertad de las partes. De ahí que en aquellas sedes en las que existen buenas razones para pensar que se presentan diferencias estructurales entre las partes - por ejemplo, relaciones de consumo o entre profesionales liberales y legos- lo que suele hacerse es dictar legislación especial. Si lo que vengo diciendo es correcto, entonces es posible afirmar que, así como resultaba incorrecta la extrapolación de las asunciones
} 
principio de buena fe contractual ${ }^{28}$, para el derecho del consumo estos están en su base. Mientras en el Código Civil y de Comercio la protección al consentimiento libre se configura por vía de reacción, anulando contratos que aparecen viciados y por causas tipificadas, en la ley de protección a los derechos de los consumidores existe un sistema preventivo, pues, se asegura al consumidor la plena información. Más que la voluntad negocial, lo que se busca es dar protección a la expectativa de un consumo seguro y de acuerdo con lo que se ha ofrecido.

\section{b) Restricciones a la libertad de contratación y a la manifestación de la voluntad de contratar}

Como idea primera, debe decirse que todo el sistema de derechos que la Ley 19.496 consagra en favor de los consumidores, se constituye en una barrera infranqueable para la libertad contractual, pues el artículo 4 estatuye que los derechos de los consumidores no pueden ser renunciados anticipadamente; en los actos de consumo, el ámbito de lo negociable queda constreñido fuertemente, a diferencia de lo que dispone el Código Civil en su artículo 12, que asegura la renuncia a los derechos conferidos por las leyes, con tal que la renuncia mire al solo interés individual del renunciante y no esté prohibida la renuncia.

Este es un aspecto que me parece central, porque pone en la raíz del sistema del derecho del consumidor un criterio protector, con lo cual el paradigma clásico del derecho civil y comercial, de la libertad de contratación queda fuertemente reducida, desde el momento que existe un elenco amplio de derechos del consumidor, que no pueden ser renun$\operatorname{ciados}^{29}$.

En cuanto a la forma o manera en que la voluntad debe ser manifestada en materia de consumo, tenemos dos disposiciones que conviene recordar, porque también aparecen parcialmente modificadas respecto a lo que es el derecho común. Por una parte, desde el punto de vista del consumidor, el artículo 3 letra a) asegura la libertad de elección del bien o servicio, y por otra, el silencio no constituye aceptación en los actos de consumo ${ }^{30}$. Esto significa que la manifestación de voluntad en los actos de consumo por parte del consumi-

de igualdad y libertad propias del derecho común a relaciones caracterizadas por la desigualdad de las partes, resulta igualmente incorrecta la extrapolación de la regulación de estas relaciones a aquellas relaciones disciplinadas por el derecho común. Dicho de forma más sencilla: resulta incorrecto extrapolar el establecimiento de un deber general de informar propio de la regulación de relaciones de consumo $-\mathrm{u}$ otras semejantes- a aquellas relaciones disciplinadas por el Código Civi”.

28 Cfr. Guzmán Brito (2002).

29 Aimone (2013) p. 5, justifica de la siguiente manera la existencia de una Ley de protección de los derechos de los consumidores: "El problema radica en que el contrato de consumo cesó de ser aquel caso que se nos enseñó en la cátedra; a saber el resultado de la deliberación entre las dos partes dotadas de poderes iguales. El contrato clásico lo forman las partes; el moderno no resiste llamar del mismo modo a quienes lo celebran, y distingue entre el estipulante, que es el representante de la gran empresa elaboradora o distribuidora, y el aceptante, que es el consumidor, cuyo rol no es más que el de aceptar, o bien, no aceptar. (...) La Ley pues o más precisamente el derecho, como en muchas otras ocasiones y circunstancias, se pone al lado del débil para que, de tal modo se restablezca la igualdad, que es la nota más importante de la justicia”.

${ }^{30}$ Fue la clave en el fallo Sernac con Cencosud, para estimar abusiva una de las cláusulas del contrato de tarjeta Jumbo Mas (Sernac con Cencosud, Corte Suprema, sentencia de 24/04/2013, Rol 12.355-11, considerando sexto de la sentencia de reemplazo). Para un comentario del fallo, véase PINOchet (2013). 
dor está sujeta a un importante restricción, entendiendo por silencio a la falta de expresión de voluntad, fundamentalmente por la vía del lenguaje, oral o escrito. En consecuencia, de la falta de manifestación o expresión de voluntad no puede derivarse aceptación del consumidor. La norma tiene interés para los efectos de analizar la posible validez de aceptaciones tácitas, es decir, de aquellas que no se derivan de una explícita, clara e inequívoca manifestación de consentimiento por parte del consumidor. Ellas no podrán admitirse con tanta amplitud como en el derecho común, pues, pueden esconder abusos, en el sentido de que el consumidor no ha conocido exactamente la propuesta que está aceptando. Incluso más, la misma disposición permite rechazar la posibilidad de que el consumidor pueda ser compelido por el proveedor, de que su no expresión se tendrá como aceptación o desistimiento. Naturalmente el acto mismo de consumo sí es aceptación, pero únicamente en cuenta expresa la voluntad de recibir el bien o servicio ofrecido. Por lo mismo, las aceptaciones tácitas, como la que acabo de referir están severamente restringidas en el derecho de consumo.

En lo que se refiere a la libertad de contratación, en su dimensión de la autonomía para escoger, ella solo está protegida para el consumidor, quien, no solo tiene derecho a la libre elección del bien o servicio a contratar, sino que, además, de acuerdo con el artículo 3 letra c) de la Ley 19.496, tiene derecho para no ser discriminado arbitrariamente, por lo que el proveedor debe someter a todos los consumidores a condiciones similares, sin distinguir entre ellos sin fundamento objetivo y racional. Más aún, el artículo 13 de la Ley dispone que "los proveedores no podrán negar injustificadamente la venta de bienes o la prestación de servicios comprendidos en sus respectivos giros en las condiciones ofrecidas". Si se aprecia, dado que el proveedor no puede incurrir en discriminaciones arbitrarias, su libertad de contratación, en la dimensión de cuándo, con quién y qué contratar, está severamente disminuida.

\section{CLÁUSULAS ABUSIVAS EN CONTRATOS DE ADHESIÓN: SU CONFIGURACIÓN}

La cuestión de las cláusulas abusivas se ha venido desarrollando con antelación a los problemas propios del derecho del consumo masivo, en conexión con los denominados contratos de adhesión, y en general en aquellos casos en que una parte impone condiciones en la celebración de un contrato, por efecto de un desequilibrio de fuerzas, que se traduce en que la otra no está en posibilidad de negociar, es decir de modificar o rechazar todo o parte de lo propuesto como condiciones de contratación. Una vez más, serán los principios de autonomía privada y buena fe contractual los que en el derecho común permitan asegurar un marco de negociación justa ${ }^{31}$. Con todo, puede decirse, de una manera general que si fue necesario dictar reglas especiales sobre cláusulas abusivas para el derecho del consumidor es porque las puras reglas derivadas de la buena $\mathrm{fe}^{32}$ y de la interpretación de los

\footnotetext{
31 Un artículo señero en esta materia para el derecho chileno es el de BAMBACH (1991).

32 Sobre el tema últimamente, véase Boestch (2011) y, de una manera general, López SANTA María (2010) pp. $337-360$.
} 
contratos no parecían suficientes para llegar a estructura un sistema eficiente, de control y sanción de los contratante abusivos, en la contratación en masa ${ }^{33}$.

La Ley 19.496, en cambio, ha regulado con precisión no solo el contrato de adhesión, sino también la cuestión de las cláusulas abusivas. Pienso, como he adelantado, que el derecho del consumo en esta parte influirá particularmente en el derecho común, pues, en él se contienen elementos que están basados en una larga maduración, particularmente europea, que bien se pueden transpolar a situaciones en donde se luche contra cláusulas abusivas y contratos de adhesión en general, más allá del ámbito de la Ley $19.496^{34}$.

En materia de contratos de adhesión ${ }^{35}$ la norma contenida en el artículo a 17 de la Ley 19.496 es exigente, pues requiere que los contratos de adhesión consten por escrito de modo claramente legible, con letra no inferior a 2,5 milímetros y en idioma castellano ${ }^{36}$. Es más, la aceptación del consumidor debe darse por medio de la firma estampada en el mismo contrato. Tenemos una aceptación expresa, mediante la firma, frente a un contrato que debe ser escriturado, bajo las reglas indicadas, de otra manera las cláusulas no producirán efecto alguno "respecto del consumidor". Esto último significa que el contrato tiene efecto eventualmente contra el proveedor, y por lo mismo, todo el sistema que se configura busca proteger solo al consumidor, en términos de asegurar su asentimiento libre, equilibrado y sin daño. Como se aprecia, y siguiendo a Wahl, "el contrato de adhesión desafía los principios tradicionales de autonomía de la voluntad, libertad contractual y formación del consentimiento" ${ }^{37}$.

El artículo 16 se propone evitar las cláusulas abusivas, para lo cual establece un amplio listado de las que considera inadmisibles, estrechando así la libertad contractual de una manera expresa; si bien algunas de ellas pudieran derivarse de las reglas generales, el listado tiene la virtud de hacer clara su ilicitud. La disposición cierra el elenco de cláusulas no permitidas, con una descripción que ofrece un encuadramiento general de lo permitido en la buena fe contractual, pero no de tipo subjetivo sino objetivo, es decir cuando, conforme con la disposición se cause un perjuicio al consumidor, por efecto de un desequilibrio importante en los derechos y obligaciones que para las partes se deriven del contrato. Para estos efectos, la ley llama a atender a la finalidad del contrato, y a las disposiciones generales o especiales que lo rigen. El profesor Carvajal tiene dicho a este respecto que "el texto

\footnotetext{
33 Cfr. Pizarro Wilson (2012).

34 Momberg (2013a) p. 490.

35 Díez-Picazo (1996) p. 368, explicando el problema de las condiciones generales de la contratación ha dicho: "El fenómeno de la contratación por medio de formularios o mediante cláusulas preestablecidas sitúa normalmente en condiciones de inferioridad la cliente o consumidor, cuyos derechos contractuales se ven recortados o disminuidos y sus obligaciones aumentadas y ocurre justamente lo contrario respecto de la posición de la parte predisponente. De este planteamiento se desprende que no es económicamente posible una prohibición total de este tipo de contratación y que las medidas de política jurídica que se deben adoptar son las de sujeción del fenómeno a un control riguroso, que impida las situaciones de abuso de la contratación, respecto de la parte contractual económicamente más débil”.

36 Los contratos de adhesión redactados en otro idioma valen solo si el consumidor los acepta expresamente bajo su firma, en un anexo que contenga la traducción castellana, versión que prevalecerá respecto de contenida en lengua extranjera.

37 WaHl (2006) p. 62.
} 
de la disposición ofrece un tenor claramente diferenciado de la concepción del contrato, y su consiguiente forma de interpretación, respecto de la que está ínsita en el libro cuarto de nuestro Código Civil (...). Contrasta con esto, que el artículo 16, letra g), en ningún momento acuda a los conceptos de 'concurso real de voluntades', o 'intención'; sino que, a 'parámetros objetivos', que como ha quedado dicho, corresponden a la finalidad del contrato' y a 'las disposiciones generales o especiales que lo rigen'" 38.

La Ley 20.555, de 5 de diciembre de 2011, vino a regular de una manera pormenorizada los contratos de adhesión que se exigen en prestaciones de servicios crediticios, de seguros y, en general, de cualquier producto financiero, elaborados por bancos e instituciones financieras o por sociedades de apoyo a su giro, establecimientos comerciales, compañías de seguros, cajas de compensación, cooperativas de ahorro y crédito, y en general de toda persona natural o jurídica proveedora de dichos servicios o productos, en donde se aprecia un severo constreñimiento de la libertad contractual, basado en la experiencia y larga tradición de excesos cometidos en esta área de la industria. Como aspectos más salientes, puede advertirse la prohibición de otorgar mandatos irrevocables o en blanco, o en que el mandatario quede liberado de su obligación de rendir cuenta (cfr. artículo 17 B), resalta también la prohibición de vender productos o servicios "atados" (artículo $17 \mathrm{H}$ ) ${ }^{39}$ y el derecho de los consumidores de poner término anticipado a uno o más servicios financieros por su sola voluntad y siempre que extingan totalmente las obligaciones con el proveedor asociadas al o los servicios específicos que el consumidor decide terminar, incluido el costo por término o pago anticipado determinado en el contrato de adhesión (artículo $17 \mathrm{D}$ inciso $3^{\circ}$ ). Por otra parte, la denuncia de cláusulas abusivas en los términos que los prohíbe el artículo 17 B, solo puede ser ejercida, para los efectos de pedir su nulidad por el consumidor y ellas no pueden ser invocadas por el proveedor para eximirse o retardar el cumplimiento parcial o total de las obligaciones que le imponen los respectivos contratos a favor del consumidor (artículo $17 \mathrm{E}$ ).

En lo que se refiere a contratación por medios electrónicos, o por vía de catálogos, avisos o por cualquier medio de comunicación a distancia, conforme con el artículo $12 \mathrm{~A}$, aparece claramente protegida la aceptación del consumidor, como elemento del consentimiento, pues este debe tener acceso claro y comprensible a las condiciones generales del bien o servicio ofrecido, y a la posibilidad de almacenarlos. La aceptación no se deduce de la sola visita al sitio, que no impone obligación alguna al consumidor, a menos de que haya aceptado de manera inequívoca las condiciones ofrecidas por el proveedor. Esto significa que el acto de aceptación debe ser ostensible, y de hecho se le asegura al consumidor el derecho a que el proveedor le envíe una confirmación, por vía electrónica o por otros medios de comunicación, que garantice el oportuno conocimiento del consumidor, la que conten-

38 Cfr. Carvajal (2012) p. 443.

39 Para este tema de las ventas atadas y en general un comentario crítico a esta reforma en lo que se refiere a este tema, véase BARRIENTOS (2012) p. 401, quien explicando por qué este tipo de ventas contraían la libertad de elección señala: "En esta caso la libertad de elección no dice relación con que no pueda comprar o adquirir por cualquier medio oneroso el bien o servicio, más bien es que no se puede adquirir de otra forma que no sea con el producto atado a él, lo que genera un perjuicio al consumidor”. 
drá una copia legible, clara e íntegra del contrato $^{40}$. Por contraste, puede apreciarse aquí cómo el valor del consentimiento del consumidor está protegido en este caso directamente en la propia ley en la Ley 19.496.

Como puede apreciarse, la regulación del denominado contrato de adhesión y de las cláusulas abusivas en particular, supera con mucho el marco general del derecho del consumo, y puede afirmarse que está basado en la idea de evitar objetivamente ciertas cláusulas. Hay por lo mismo, una intensidad regulatoria que es desconocida en el derecho común, y a la cual difícilmente se podría llegar aplicando los principios clásicos ${ }^{41}$, y que ciertamente irradiará más allá de su ámbito de acción, por disposición legal.

\section{EL PACTA SUNT SERVANDA Y LOS ACTOS DE CONSUMO}

Una vez celebrado un acto de consumo, los términos en que este debe ejecutarse superan con mucho a la regla del pacta sunt servanda o de la intención de los contratantes como regla matriz para ejecutar un contrato, según antes recordábamos. En efecto, el mismo artículo 12 de la Ley 19.496 indica como principal deber legal del proveedor el de respetar los términos, condiciones o modalidades ofrecidas, norma similar al artículo 1545 del Código Civil. Sin embargo, no existe una regulación recíproca para el consumidor, al que se le reconoce, en algunos casos, el derecho de retracto, en los términos que establece el artículo 3 bis de la Ley $19.496^{42}$.

Si se revisa con atención el contenido mismo de lo que el proveedor debe dar o prestar, ello no lo determina exclusivamente el contrato, es decir lo estrictamente convenido, pues, la lectura del artículo 20 de la Ley 19.496 permite afirmar que existe un ámbito de protección del consumidor que tiene carácter amplio y objetivo, en el sentido que debe darse o prestarse la cosa o servicio ofrecido, más allá de los términos que pudieran haberse pactado $^{43}$. De hecho, el artículo 19 confiere al consumidor el derecho de reposición del bien, a la devolución del dinero pagado en exceso, o la bonificación de su valor para la compra de otro producto, cuando no hubiera recibido una cantidad o contenido neto de un producto distinto de la que aparece en el "envase o empaque". Es decir, no es la con-

\footnotetext{
40 Sobre este tema, véase Pinochet (2007) passim.

41 Una justificación de este tipo de intervenciones legislativas, se encuentra en STIGLITz y STiglitz (1985) pp. 3-4: "Y es entonces ese mismo sistema jurídico tradicional, fundado en los ideales liberales e individualistas y fiel garante de la libertad económica absoluta de los hombres (igualdad formal), el que ahora, frente al desequilibrio desencadenado en las relaciones de consumo, se revela impotente para recrear una efectiva igualdad real".

42 Pinochet (2006) p. 85 "El fundamento de tal derecho, en líneas amplias, se encuentra en el mismo motivo que inspira toda la normativa de consumo, estos es, estructurar un sistema de protección al consumidor, considerando este último como la parte débil de la relación contractual, frente a la parte fuerte, el profesional. En tal sentido, debe considerarse la desproporción de fuerzas en que se encuentran -la mayoría de las veces- los contratantes en los contratos de consumo y las agresivas campañas de marketing y publicidad que desarrollan las empresas, lo que hace que las características objetivas de un producto puedan verse distorsionadas. Esto puede provocar que el consumidor espere una serie de atributos de los bienes y servicios que consume, no objetivos, que pueden ser factor determinante en su decisión de compra. En consecuencia, debe quedar bajo riesgo y responsabilidad del proveedor el hecho de que el producto ofrecido y publicitado no cumpla, en definitiva, las expectativas que ciertamente ha provocado en la psiquis del consumidor".

43 Para un estudio del artículo 20 de la Ley 19.496, véase Barrientos (2011).
} 
vención la que en estos casos determina lo que se debía, sino lo que objetivamente estaba indicado, como cantidad o peso contenido, en el bien o producto.

Como colofón de lo que venimos expresando, puede decirse que en la Ley de protección de los derechos de los consumidores no es el consentimiento en sí mismo el que está protegido, sino el acto de consumo, cuyo marco de configuración no está dado por el hecho de que se haya producido un acuerdo entre proveedor y consumidor respecto de un determinado acto o contrato, sino por el hecho de que efectivamente se haya consumido. Mientras en el sistema civil y comercial el consentimiento (la voluntad negocial) configura la protección que busca el Derecho, en los actos de consumo se protege, como ya se dijo, la confianza del consumidor, y de una manera objetiva, es decir sin mayores indagaciones hacia a la voluntad negocial.

\section{LAS CONSECUENCIAS QUE DERIVAN DEL INCUMPLIMIENTO DE LA LEY}

\subsection{LA GARANTÍA LEGAL}

A continuación me refiero a las consecuencias o efectos que se derivan del incumplimiento de la Ley 19.496, en comparación con las reglas generales sobre incumplimiento contractual. Estoy bien consciente que en esta materia la ley que estudio ofrece un sistema disperso, y con serias falencias de consistencia, lo que se ha prestado para muchas dificultades interpretativas; tal vez la más saliente es el marcado carácter contravencional que se le ha dado a sus disposiciones, ello seguramente influido por la ley que la precedió ${ }^{44}$.

Como se sabe, la doctrina tradicional chilena explica que del incumplimiento de una obligación pueden derivar varias consecuencias, entre ellas, la ejecución forzosa de la misma, los daños y perjuicios y otros derechos auxiliares del acreedor ${ }^{45}$. Esta estructura aparece ampliada y reforzada en el sistema de remedios procesales que ofrece la Ley 19.496.

La Ley de protección de los derechos de los consumidores tiene un carácter mixto, porque junto con consagrar acciones reparatorias derivadas del incumplimiento, también establece sanciones contravencionales que están penadas con multas (entre otras artículos 9, $12,13,14,31,32,33,35$, inciso $3^{\circ}, 23$ inciso $2^{\circ}, 29,45$ inciso $1^{\circ}$, y sin perjuicio de contemplar una sanción residual en el artículo 24 inciso $\left.1^{\circ}\right)^{46}$. Se ha discutido la conexión que existen entre ambas, dada la competencia que, como regla, la Ley le confirió a los Juzgados de Policía Local. Para una amplia jurisprudencia es presupuesto de las acciones civiles el que pueda perseguirse la responsabilidad contravencional, la que conforme con el artículo 26 de la Ley, prescribe en 6 meses desde que se ha incurrido en la infracción respectiva, lo que supondría que pasado este plazo, al perder el tribunal la competencia para sancionar la infracción, tampoco podría ejercerse la acción civil indemnizatoria, por ejemplo. Aunque la

\footnotetext{
44 Ley 18.223.

45 También deben agregarse la acción resolutoria, en los casos de obligaciones que emanan de contratos bilaterales, o la facultad de ejercer el derecho legal de retención en los casos que la ley lo autoriza, entre otros derechos. Por todos, véase ABELIuK (2001) pp. 459-5025.

46 Cfr. Bofill (1999).
} 
doctrina correcta parece ser la que postula la autonomía de ambas acciones ${ }^{47}$, tema que fue zanjado en el fallo Sernac-Cencosud ya referido.

La Ley de protección de derechos de los consumidores confiere al afectado, entre otros derechos, lo que se ha denominado la responsabilidad derivada de la garantía legal, que conforme con el artículo 20 la Ley 19.496, ofrece varias opciones, todo ello sin perjuicio del derecho a la indemnización por los daños ocasionados. Existen en este caso cuatro acciones distintas: i) la reparación gratuita del bien; ii) la reposición del bien (previa devolución de lo recibido); iii) la restitución de la cantidad pagada (previa devolución de lo recibido); iv) la indemnización complementaria por los daños causados, todo lo cual demuestra el amplio espectro de acciones que la ley de protección de los derechos de los consumidores ofrece en caso de venta de un producto.

Paralelamente, tenemos la responsabilidad civil derivada del ilícito infraccional, contemplados en un serie de disposiciones, entre otras el artículo 23 y que está formulada de la siguiente manera: "Artículo 23.- Comete infracción a las disposiciones de la presente ley el proveedor que, en la venta de un bien o en la prestación de un servicio, actuando con negligencia, causa menoscabo al consumidor debido a fallas o deficiencias en la calidad, cantidad, identidad, sustancia, procedencia, seguridad, peso o medida del respectivo bien o servicio".

\subsection{LOS CONTRATOS DE PRESTACIÓN DE SERVICIOS}

Respecto de las prestaciones de servicios, también cabe destacarse el deber u obligación de garantía legal, con amplia cobertura de servicios, según se lee del artículo 41, y que consiste en la necesidad en que queda el proveedor de responder por el servicio prestado y de su reparación, dentro de un plazo que debe indicar en el recibo, escrito o boleta que entregue. Esta garantía apunta a asegurar la reiteración del servicio, la devolución del precio recibido, si fuere del caso, y a la indemnización de todo otro perjuicio al consumidor ${ }^{48}$. En el artículo 40 de la Ley 19.496, se dispone que en los contratos de prestación de servicios cuyo objeto sea la reparación de cualquier tipo de bienes, se entenderá implícita la obligación del prestador del servicio de emplear en tal reparación componentes o repuestos adecuados al bien de que se trate, ya sean nuevos o refaccionados, siempre que se informe al consumidor de esta circunstancia. El incumplimiento de esta obligación dará lugar, además de las sanciones e indemnizaciones que procedan, a exigir la sustitución de los componentes o repuestos correspondientes, sin cargo adicional.

\footnotetext{
47 Sobre este tema Guerrero Bécar (2008) passim, quien aboga por una distinción de las distintas contravenciones que podrían considerarse, diferenciando entre una infracción sin incumplimiento contractual; el incumplimiento contractual propiamente tal; y las situaciones mixtas. Con ello disocia la necesaria unidad que la mayoría de la jurisprudencia de policía local, planea entre infracción administrativa o contravencional e incumplimiento contractual.

48 Cfr. Rodríguez Pinto (2006) pp. 115-117.
} 


\subsection{LAS ACCIONES GENERALES}

\section{a) Cumplimiento de la prestación y cesación del acto ilícito}

A esas acciones especiales deben agregarse las generales que derivan de lo dispuesto en el artículo 50, en las cuales destaco el derecho a obtener la prestación incumplida y el derecho a hacer cesar el acto por el cual se afecta un determinado derecho de un consumidor, consagrado en la ley.

\section{b) La nulidad de las cláusulas abusivas}

i) Ideas generales. Como una acción adicional, y de la que no puede dudarse su función protectora del consumidor afectado, detectamos la declaración de nulidad de las cláusulas abusivas que se establece en la Ley 19.496, conforme con las reglas contenidas en sus artículos 16 y siguientes. Puede advertirse que es la propia ley la que sanciona con amplia ineficacia a las cláusulas de adhesión abusivas introducidas en un contrato de adhesión, bajo los siguientes términos: "No producirán efecto alguno en los contratos de adhesión las cláusulas o estipulaciones que...”. Es decir, la ineficacia de este tipo de cláusulas deriva directamente de la ley, y la intervención del juez debe limitarse a constatar el carácter de abusivo de una cláusula y declarar su nulidad, según se desprende del artículo 16 A.

ii) El tipo de sanción. Un tema que es interesante despejar, dice relación con la calificación que debe dársele a la nulidad de las cláusulas abusivas, si inexistencia, nulidad absoluta o, incluso, relativa ${ }^{49}$.

Me parece que la función protectora que de la Ley de protección de los derechos de los consumidores tiene, impide aplicar la reglas de la nulidad absoluta sobre saneamiento ${ }^{50}$ a la nulidad de las cláusulas abusivas, por distintas de razones, tal vez la más importante porque en general me parece que la nulidad de las cláusulas abusivas contenida en la Ley 19.496, lo que busca es precisamente no darle eficacia a una cláusula abusiva. No me parece razonable aplicar en subsidio el Código Civil en este caso, porque una cláusula abusiva causa un daño permanente a un consumidor y ello justifica que nunca pueda ser saneada, pues, el daño futuro no puede estar amparado nunca, porque con ello se estaría violentando, en su base, el espíritu de la ley, que justamente pretende proteger los derechos de los consumidores, basado en principios de orden público ${ }^{51}$. Ninguna razón lógica podría hacer que una cláusula, que no se ha detectado oportunamente como abusiva, pudiera quedar al margen de la declaración de nulidad, por el hecho de haber estado operativa en el tiempo, en este caso

\footnotetext{
49 Para el derecho español, véase MiQuel, (2002) pp. 474-475, quien declara que la sanción de una cláusula abusiva es la nulidad de pleno derecho (artículo 9 y 10 de la Ley española sobre Condiciones Generales de Contratación), pero aclara que sería relativa, pues, la ineficacia opera únicamente en perjuicio del adherente.

50 Así las califican, entre otros, TAPIA y VALdivia (1999) p. 161; HüBner (1999) p. 136, opinión que sigue WAHL (2006) p. 70-71. Recientemente Lorenzini y Polit (2013), con desarrollo, pp. 476-478.

51 Para el derecho brasileño se afirma que la acción de nulidad de estas cláusulas no es prescriptible, precisamente basado en que la nulidad la declara la ley, tiene su fuente en el orden público y el interés social, y la sentencia que tiene el carácter constitutiva, cfr. NunEs (2011) pp. 656-662.
} 
10 años. Por ello, no creo que el estatuto supletorio que las rige sea el de la nulidad absoluta, contenido en el Código Civil, pues, entre otras cosas, ello supondría estimar que podrían sanearse por el transcurso del tiempo, conforme lo dispone el artículo 1683, in fine.

Para confirmar que no puede aplicarse el estatuto de la nulidad absoluta del código Civil, irreflexivamente, téngase presente el inciso segundo del artículo $16 \mathrm{E}$ que dispone que la nulidad de una cláusula de adhesión declaradas como abusivas por el artículo $16 \mathrm{~B}$, no podrá invocarse por el consumidor afectado para eximirse o retardar el cumplimiento parcial o total de las obligaciones que le imponen los respectivos contratos a favor del consumidor. Si se advierte, la limitación es funcional, y no puede derivarse que la cláusula sea válida, sino que el proveedor está inhibido de asilarse en ella para dejar de cumplir o retardar total o completamente sus obligaciones. Se trata de un instrumento legal -la nulidad-, que busca proteger a los consumidores y no causarles un detrimento, el que se derivaría del hecho que un proveedor, asilado en la nulidad, pudiera dejar de cumplir sus compromisos ${ }^{52}$.

Entiendo, en consecuencia, que frente a la denuncia de una cláusula como abusiva, y que sea estimada, ella debe ser expulsada del contrato, y ninguna prescripción, caducidad o saneamiento podría reclamarse para conferirle valor. Cuestión distinta son las consecuencias patrimoniales que puedan derivarse de la declaración de nulidad, como por ejemplo las restituciones que pudieran reclamarse, o incluso las acciones contravencionales que pudieran deducirse, que sí están sujetas a prescripción. Las primeras, conforme con las reglas generales, y las segundas, en el plazo de 6 meses, de acuerdo con lo que dispone el artículo 26 de la Ley 19.496.

Confirmo, entonces, que la sanción de ineficacia por nulidad que la Ley 16.946 establece, es un formidable instrumento de protección de los derechos de los consumidores, que debe ser comprendido en su verdadera peculiaridad y profundidad ${ }^{53}$.

\footnotetext{
52 Larroumet (1998) p. 60, tiene dicho: “...la sanción por infracción de una regla imperativa en materia de contratos es la nulidad de la estipulación contraria a dicha regla imperativa. Se trata de una nulidad de pleno derecho, lo que significa que el juez tiene la obligación de declararla sin disponer de un poder de apreciación que le permitiría decidir si la estipulación prohibida debe o no ser anulada”.

53 Pasquau (1997) p. 232, tiene dicho lo que sigue, para el derecho español: "Liberado de la lectura reduccionista que lo quiere referir exclusivamente a los casos de anulabilidad, el artículo 1302 no es más que la expresión de claros principios generales, como el que prohíbe ir contra propios actos y el que prohíbe el abuso del derecho. El que la nulidad esté dispuesta para proteger a una parte contractual frente a otra (bien por razones a coyunturales que tengan que ver con el proceso de formación de la voluntad, bien por razones más objetivables que tome en cuenta la "categoría" a la que pertenece la parte protegida: consumidor, prestatario, asalariado, arrendatario, etc.), no tiene por qué conducir necesariamente a la anulabilidad. Ello se advierte con claridad en las llamadas relaciones contractuales asimétricas, en las que la desigualdad en la que concurren las partes al contrato es una desigualdad no económica, sino una desigualdad de condición o categoría: se quiere proteger a una categoría de personas frente a determinados desequilibrios típicos que se generan en los contratos en que intervienen (déficit de información, situación de necesidad, falta de negociación precontractual): la nulidad se utiliza entonces como una técnica de control del contenido contractual que favorece a una parte predeterminada frente a la otra; pero la nulidad no es disponible, sino que el Derecho ha optado ya por ella, con independencia de la voluntad de cada contratante protegido. De lo contrario, por ejemplo, no sería posible -o exigiría alguna complicada explicación- una acción colectiva que persiguiera la declaración de nulidad de una determinada cláusula contractual colectiva. Parece pues que la cláusula o el contrato son nulos de pleno derecho, pero cuesta poco trabajo llegar a la conclusión de que la parte protegida por dicha nulidad no está legitimada para instalarla: basta para ello con recordar que la nulidad no es un estado del acto, algo que se imponga sobre
} 
Por último, en materia de protección de los derechos del consumidor, es clave la cuestión de los intereses colectivos o difusos ${ }^{54}$, que fue introducida por la Ley 19.955, y tal vez es el área donde mejor se noten estos nuevos paradigmas. En efecto, la materia misma del ámbito protegible (intereses colectivos o de grupo), como también la manera en que ello debe hacerse, supone que la persona, como ser individual y autónomo, queda recogida en la noción de grupo o colectivo, o asociación de interesados, que pueden instar como tales en pro de sus congéneres o asociados. Esto significa que el bien protegido supera el mero interés individual, y queda incluido en la esfera colectiva, por lo que el juez debe valorar al momento de resolver la cuestión que se le someta, y atender a las consecuencias que su decisión pueda causar en otras personas que puedan estar en situaciones semejantes.

\section{LA RESPONSABILIDAD CIVIL EN LA LEY 19.496}

\subsection{LAS PRINCIPALES DIFERENCIAS}

\section{a) La infracción legal y contractual}

Un tercer aspecto en que existe una marcada diferencia entre la Ley 19.496 y las normas que regulan los contratos civiles y comerciales, es en materia de la responsabilidad civil derivada del incumplimiento de un contrato. Mientras en derecho común los elementos básicos para configurar la responsabilidad civil, de carácter contractual son: a) que se haya incumplido una obligación; b) que al deudor le sea imputable la infracción; c) que ese incumplimiento haya causado un daño al acreedor; d) que el deudor esté en mora. Sin embargo, en la ley de protección a los derechos de los consumidores, las reglas son algo distintas.

Dado que el ámbito de lo protegido en la Ley 19.496 es diferente a los contratos civiles y comerciales, es obvio que las fuentes que gatillan el incumplimiento difieren. Puede decirse que el contrato que sustenta el acto de consumo se convierte en un elemento o instrumento que sirve de cauce para generar la responsabilidad, pero no es estrictamente el aspecto central. Lo determinante es que, en el marco de un acto de consumo, se haya incumplido por parte del proveedor la Ley 19.496. Por ello resulta difícil hablar en este caso de responsabilidad contractual. Lo anterior no obsta, naturalmente, a que también pueda exigirse la responsabilidad que deriva del derecho común ${ }^{55}$. El inciso segundo del artículo 50 describe el supuesto que genera el incumplimiento y la amplitud de los efectos que se des-

toda otra consideración como se impone la naturaleza, sino una reacción de carácter reactivo e instrumental, bien para perseguir positivamente determinada finalidad en el ámbito negocial, bien para impedir que la fuerza obligatoria de los contratos dé cobertura a intereses espurios: lógico parece, desde esta perspectiva, ajustar la legitimación a los fines cuando estos caractericen la nulidad, y permitir un control de legitimidad del interés que quiere hacerse valer al accionar la nulidad, un control a efectuar preciosamente desde la ratio de la norma que establece la nulidad".

54 Aguirrezabal (2006) p. 156. "Para diferenciar el interés colectivo del difuso se ha utilizado el criterio de determinación de los miembros del grupo titular de ese interés, encontrándose ante un interés colectivo, si los miembros del grupo son determinados o son fácilmente determinables, y un interés difuso si se trata de un conjunto indeterminado de consumidores afectados".

55 Fue justamente este tipo de situaciones, de superposición de normativas, a las que hace referencia CAPRILE en el trabajo que motivó esta reflexión, véase nt. 1. 
encadenan: "El incumplimiento de las normas contenidas en la presente ley dará lugar a las acciones destinadas a sancionar al proveedor que incurra en infracción, anular las cláusulas abusivas, incorporadas en los contratos de adhesión, obtener la prestación de la obligación incumplida, hacer cesar el acto que afecta el ejercicio de los derechos de los consumidores, a obtener la debida indemnización de perjuicios o la reparación que corresponda" 56 .

Otra norma que alumbra la especialidad que estamos pergeñando, podemos encontrarla en el artículo 2 bis letra c) de la Ley, por la cual se establece un derecho subsidiario a favor del consumidor, para áreas del consumo masivo sujetas a ley especial, por la cual se le reconoce el derecho a ser indemnizado de todo perjuicio originado en el incumplimiento de una obligación contraída por el proveedor respectivo, y siempre que no existan procedimientos indemnizatorios en la ley respectiva. Es obvio que al existir reglas generales de responsabilidad civil contractual, una norma como esta se justifica, si el legislador entiende que la indemnización contemplada en la Ley 19.496 tiene especialidad, y no solo por la cuestión procedimental.

Dentro de los bienes que la ley de protección de los derechos del consumidor protege, resaltamos el deber legal del proveedor de ofrecer a los consumidores seguridad en el consumo de bienes y servicios, de no dañar su salud y el medio ambiente, hasta el grado de evitar los riesgos que pudieran afectarle, todo ello conforme con lo dispuesto en el artículo 3 letra d) de la Ley 19.496 ${ }^{57}$. Esta norma debe ser coordinada con el artículo 23 de la misma ley, ya recordado, pues, si un proveedor, por negligencia, causa menoscabo a un consumidor, debido a fallas o deficiencias en la calidad, cantidad, identidad, sustancia, procedencia, seguridad, peso o medida del respectivo bien o servicio ${ }^{58}$.

Por lo tanto, el deber de seguridad en el consumo no viene dado por el contrato mismo, ni siquiera por el deber general de comportarse de buena fe que tiene todo proveedor, sino por disposiciones contenidas en la misma Ley. Su infracción, es antes que nada, un quebrantamiento o contravención legal ${ }^{59}$ que entronca con el artículo $19 \mathrm{~N}^{\circ} 1$ de la Constitución, en relación con el artículo primero de la misma Carta, que asegura a todas las personas el derecho a la vida y a la integridad psíquica y física de toda persona, y pone como deber del Estado dar protección a la población. De hecho, en la Constitución la sa-

\footnotetext{
56 La Ley 19.955 vino a mejorar la técnica legislativa, pues se había advertido que existían acciones, bajo la primitiva norma de la Ley 19.496, que no estaban desarrolladas, tal es el caso de la nulidad de las cláusulas contenidas en los contratos de adhesión (artículo 16); la discriminación arbitraria que puede sufrir un consumidor (artículo 3 letra c); el daño moral que puede sufrir un usuario o consumidor cuando los sistemas de seguridad y vigilancia afecten su dignidad y derechos (artículo 15); los casos de suspensión, paralización o negativa injustificada a la prestación de un servicio previamente contratado y por el cual se hubiere pagado un derecho de conexión, de instalación, de incorporación o de mantención, cfr. Romero (1999) p. 328.

57 Sobre este tema últimamente Barrientos Zamorano (2013), para casos de daños en estacionamientos de centros comerciales.

58 Sobre este tema Corral (2006) p. 103: "Parece evidente que en esta situación, junto con la sanción por la infracción, procederá una acción de responsabilidad civil para reclamar la reparación del daño o menoscabo causado. El supuesto es muy interesante, porque prevé expresamente que se causen daños derivados de la falta de seguridad del producto, lo que constituye el elemento fundamental del régimen de responsabilidad por productos defectuosos", también (1999).

59 Para un estudio de esta disposición, véase BARrientos (2010).
} 
lubridad pública se erige como uno de los elementos que configuran la función social de la propiedad.

Pero no se queda aquí la Ley de protección de los derechos de los consumidores, porque el artículo 3 letra e) consagra en favor del consumidor el derecho a ser reparado e indemnizado adecuada y oportunamente respecto de todos los daños materiales y morales, en caso de incumplimiento de cualquiera de las obligaciones contraídas por el proveedor. Esta norma es muy relevante, desde el momento que confiere al consumidor el derecho a la reparación como efecto de un incumplimiento de obligaciones contraídas por el proveedor.

En consecuencia, y analizando las fuentes por las cuales el proveedor puede responder por daños y perjuicios causados en una actividad de consumo regida por la Ley 19.496, podemos distinguir, por un lado el daño que se deriva de la afectación de un bien directamente protegido por la Ley, como es la salud. También puede reconocerse otra acción derivada de haberse causado un menoscabo al deudor por efecto de deficiencias del bien comprado por fallas o deficiencias en la calidad, cantidad, identidad, sustancia, procedencia, seguridad, peso o medida del respectivo bien o servicio. En este caso, la exige un especial factor de imputación, cual es que el proveedor haya actuado con negligencia. Un tercer factor que puede desencadenar la responsabilidad, con carácter de cláusula general, es el daño derivado de la infracción a la Ley, y que no tenga tipificado una conducta o daño especial. El cuarto factor que permite exigir responsabilidad civil, al amparo de la Ley 19.496, es el incumplimiento de contrato de consumo, que no tenga tipificación especial.

\section{b) Extensión de los daños}

La Ley de protección de los derechos de los consumidores es especial, además, por la extensión de los daños indemnizables que consagra, que es amplia. Desde luego porque no solo consagra el derecho a ser indemnizado, sino que también a ser reparado, con lo cual, con dos palabras distintas, se connota el sentido que se quiere expresar, cual es que existe un derecho a un amplio y total restablecimiento de parte del consumidor, en naturaleza de ser posible, o subsidiariamente una reparación pecuniaria, que tiene que ser "adecuada" y "oportuna”, como se ha destacado previamente en la misma norma. Y, adicionalmente, los daños que deben ser indemnizados y reparados no son solo los materiales, sino también los morales, dando aquí cabida a la reparación del daño moral, que en el sistema del Código Civil y Comercial solo ha encontrado acogida de la mano de la doctrina y de la jurisprudencia ${ }^{60}$.

En la línea de reforzar la amplitud de la reparación configurada, reitera la norma que los daños que deben ser reparados son "todos", es decir, sin dejar a ninguno de lado. Advierto, además, que no existe una referencia causal precisa entre incumplimiento y daño, pues, simplemente se expresa que todos los daños deben repararse "en caso de incumplimiento", con lo cual, me parece que el vínculo causal típico de la responsabilidad civil contractual, conforme lo dispone el artículo 1558 en su inciso primero del Código Civil, prácticamente desaparece y se acerca más al de la responsabilidad extracontractual, porque se trata más de daños causados de daños ocasionados (la ocasión en un factor de conexión más amplio que la causalidad, me parece).

${ }^{60}$ Cfr. Domínguez (2000). 


\section{c) El factor de imputación}

Uno podría preguntarse qué queda en consecuencia de la responsabilidad civil contractual clásica ${ }^{61}$, y pudiera pensarse que es el factor de imputación, pues, no es una ley que consagre responsabilidad objetiva.

Desde luego no lo puede ser la responsabilidad derivada del artículo 23 de la Ley 19.349, en donde expresamente se exige que el menoscabo que se le causa al consumidor, provenga de la negligencia del proveedor. Pero, como en los otros casos se exige que la infracción venga dada por una vulneración legal, estimo que no hay necesidad de indagar nuevos factores de imputación, pues basta esa culpa infraccional.

\subsection{LA AMPLIACiÓN DE LA ESFERA DE LOS SUJETOS RESPONSABLES}

En materia del derecho a la reparación que establece el artículo 20 de la Ley 19.496, conforme con lo que dispone su artículo 21, el consumidor podrá dirigirse, indistinta o conjuntamente, al vendedor, al fabricante o al importador. También hace responsable, de manera solidaria por los perjuicios causados al consumidor, al proveedor que haya comercializado el bien y el importador que lo haya vendido o suministrado. Por otra parte, el inciso $4^{\circ}$ del artículo 21 dispone que las otras acciones a que se refiere el inciso primero del artículo 20, podrán también hacerse valer, de manera indistinta, en contra del fabricante o el importador, en caso de ausencia del vendedor por quiebra, término de giro, u otra circunstancia semejante, excepto que se pida la devolución de la cantidad pagada, que no podrá intentarse sino respecto del vendedor.

También es relevante la norma contenida en el artículo 43, la cual hace directamente responsable al intermediario en la prestación de un servicio, y sin perjuicio de la responsabilidad del proveedor, por el incumplimiento de las obligaciones contractuales ${ }^{62}$. Por su parte, el artículo 47 también amplía la esfera de los responsables en el ámbito de los productos defectuosos, cuando dispone que declarada judicialmente o determinada por la autoridad competente de acuerdo a las normas especiales a que se refiere el artículo 44, la peligrosidad de un producto o servicio, o su toxicidad en niveles considerados como nocivos para la salud o seguridad de las personas, los daños o perjuicios que de su consumo provengan serán de cargo, solidariamente, del productor, importador y primer distribuidor o del prestador del servicio, en su caso. Es decir, puede haber cuatro responsables directos: productor, importador, primer distribuidor y proveedor.

\subsection{LOS SUJETOS ACTIVOS LEGITIMADOS}

En cuanto al sujeto legitimado, la discusión está abierta, pero ya existen voces autorizadas que amplían el ámbito de los sujetos que pueden demandar directamente las acciones que confiere el derecho del consumidor, a fin de dar protección no solo a quien

\footnotetext{
61 Zelaya (1999) p. 232-250, estudiando la Ley en su formulación anterior a la Ley 19.955, hacía una estricta interpretación de las reglas que consagran el derecho a la indemnización, para postular que lo que no se podía demandar como daño en sede del derecho del consumidor, debe reclamarse conforme con el derecho común, que para el autor parece ser el criterio del legislador.

${ }_{62}$ Sin perjuicio de su derecho a repetir contra el prestador de los servicios o terceros que resulten responsables.
} 
adquirió el bien a título oneroso, es decir al consumidor jurídico ${ }^{63}$ o la parte en términos del derecho común- sino incluso a quienes son técnicamente considerados como consumidores materiales ${ }^{64}$, o reales, pues son los que usaron o consumieron efectivamente el bien, o recibieron el servicio, y que han resultado dañados o vulnerados en sus derechos, como consecuencia u ocasión de ello. La evolución futura, no lo dudo, llevará a esta doctrina a dominar en la jurisprudencia, como ya se atisba en algunas sentencias ${ }^{65}$.

\subsection{UNA RESPONSABILIDAD PECULIAR}

Por lo que se ha dicho, no es aventurado calificar esta responsabilidad civil como especial y peculiar, porque la fuente de la misma es la Ley 19.496 y la vulneración del contrato o la obligación que ha dado lugar al acto de consumo, es solo un presupuesto que desata la responsabilidad. Tanto así, que el inciso final del artículo 50 de la Ley 19.496 dispone que, para los efectos de determinar las indemnizaciones o reparaciones que procedan, de conformidad con las normas señaladas en el párrafo segundo Título II de la ley, es preciso acreditar el daño y el vínculo contractual que liga al infractor con los consumidores afectados, sin que se haga referencia al nexo causal que debería concurrir entre incumplimiento y daño, conforme con los cánones clásicos. Es peculiar, adicionalmente, porque la reparación o indemnización ha de ser amplia y oportuna respecto de todos los daños causados, incluyendo daños materiales y morales, con lo cual se aparta de las normas de los artículos 1556 a 1559 del Código Civil, en donde los perjuicios indemnizables dependen del factor de imputación, de la mayor o menor previsibilidad del daño y de su vinculación con el incumplimiento, según los varios casos. Adicionalmente, no parece ser la mora del deudor un presupuesto para cobrar daños y perjuicios, pues, se atentaría contra el requisito de la amplitud de la indemnización, que la ley impone. En caso de restituciones e indemnizaciones

\footnotetext{
63 Es la doctrina, entre otros, de JARA (1999).

64 Cfr. Pinochet (2011) pp. 343-367; Momberg (2013) pp. 3-16.

65 "11. Que no hay aquí incumplimiento de una obligación contractual, o un acto jurídico oneroso, ya que la oferta es un paso previo a la celebración del contrato mismo, es decir, una responsabilidad precontractual, que nace a la vida del derecho antes de perfeccionarse el contrato que le servirá de fuente. En todos estos casos permite sostener que el concepto de consumidor que menciona el artículo1 No 1 de la Ley No 19.946, no le es aplicable solo a ese marco conceptual, sino que al demandante que como consumidor y habiendo sufrido una descarga eléctrica en el producto ofrecido no alcanzó ejecutar el "acto jurídico oneroso" . El caso se produjo el 23 de noviembre de 2003, aproximadamente a las 19:00 horas, don Emiliano Andrés Arias Madariaga concurrió al local de SODIMAC S.A., sucursal Talcahuano, con el objeto de adquirir diversos productos, y al momento de coger una lámpara de pie que había elegido, la que había sido conectada al toma corriente por un vendedor, sufrió una descarga eléctrica que le provocó quemaduras en su mano derecha. Corte de Apelaciones de Concepción, 24/12/2007, 174-2005)”.

"Que, finalmente, el concepto de consumidor está construido sobre la base de un sujeto que adquiere, utiliza o disfruta como destinatario final de un determinado bien o servicio. El acto jurídico que menciona el artículo 1 No 1 de la Ley 19.946, es el factor de atribución que permite imputar a un proveedor determinado los efectos de este cuerpo legal; pero los afectados por esta relación de consumo pueden ser otros sujetos que no intervinieron en el acto jurídico, como en el caso de autos, toda la familia Sepúlveda Bouniard que consumió la pasta de pollo y de huevo que ocasionó la intoxicación alimentaria”. Se trata de una intoxicación alimentaria, que también afectó a dos hijos de la persona que compró una pasta de pollo en descomposición, se condenó a la demandada por los daños que estas personas sufrieron, no obstante no haber sido quienes compraron el producto que les causó el daño. Corte de Apelaciones de Concepción, 8/11/2007, 500-2005”
} 
dinerarias, los intereses no necesariamente agotan la reparación e indemnización, y ello sin perjuicio del derecho al reajuste que confiere al consumidor el artículo 27 de la Ley 19.946.

\section{PRINCIPALES CONCLUSIONES}

Esta mirada panorámica y comparativa a la Ley 19.496, que regula los actos de consumo, en relación con las reglas del derecho común que rigen los contratos, permite concluir que entre los principios y normas que informan el sistema de la protección de los consumidores y las del derecho común, civil y comercial, existen diferencias que son muy marcadas, y que en general se basan en los distintos valores y principios que se proponen preservar y proteger uno y otro sistema.

Mientras en el derecho del consumo regidas por la Ley 19.496 el valor de la transparencia y de la confianza, apunta a dar seguridad y confianza en el consumo, imponiendo amplios deberes de información desconocidos en el derecho común, en el derecho privado es la libertad de pacto lo que se protege, y con ello se aspira a que cada cual cautele sus propios intereses, como la mejor garantía de un acuerdo justo.

La regulación del contrato de adhesión y de cláusulas abusivas contenida en la Ley 19.496, por la condensación doctrinal que representa, tiene fuerza y densidad dogmática suficientes como para influir en el derecho común.

En cuanto a las consecuencias derivadas del incumplimiento, hay muchas diferencias entre ambos sistemas, que derivan de los distintos bienes protegidos que uno y otro sistema se derivan. En este sentido destaca la declaración de nulidad que la ley hace de las cláusulas abusivas, que se erige como vía de protección del consumidor y que parecen tener un régimen especial.

Por último, la responsabilidad civil de la Ley 19.496 se acerca más a la responsabilidad extracontractual que a la contractual, sin dejar de ser especial, dadas las normas peculiares por la que se rige. Daño indemnizable, objetivación de la responsabilidad, sujetos responsables, personas protegidas, aspectos todos que dan cuenta de una especialidad, sin correspondencia en el sistema común.

Es un desafío para los estudiosos del derecho buscar una adecuada integración entre el sistema del derecho común con el de la Ley 19.496, de modo de que el derecho del consumo se pueda beneficiar de la larga experiencia acumulada por aquel. Ha de cuidarse de que esta integración no sea forzada, pues, ello puede llevar a desconocer la especialidad y peculiaridad del derecho del consumo, a fin de no hacerle aplicable normas del derecho común que podrían aparecer disfuncionales.

\section{BIBLIOGRAFÍA CITADA}

Abeliuk Manasevhich, René (2011): Las Obligaciones, Tomo II (Santiago, Editorial Temis S.A.-Editorial Jurídica de Chile, Bogotá, cuarta edición actualizada y aumentada). AguirrezabalGrunstein, Maite (2006): "El procedimiento para la defensa de intereses colectivos y difusos de consumidores y usuarios de la ley 19.496", en Baraona, Jorge y Lagos, Osvaldo (edit.), La Protección de los derechos de los consumidores en Chile, Cuader- 
nos de Extensión Jurídica 12 (Santiago, Universidad de los Andes, Facultad de Derecho) pp. 143-173.

Aimone Gibson, Enrique (2013): Protección de derechos del consumidor (Santiago, LegalPublishing Thomson Reuters).

Bambach Salvatore, M. Victoria (1991): “Las cláusulas abusivas”, en Barros, Enrique (coord.) Contratos (Santiago, Editorial Jurídica de Chile) pp. 47-79.

Barcia Lehmann, Rodrigo (2006): "La autonomía privada como principio sustentador de la teoría del contrato y su aplicación en Chile”, en De la Maza, Iñigo (edit.) Temas de Contratos, Cuadernos de Análisis Jurídicos, Colección Derecho Privado III (Santiago, Ediciones Universidad Diego Portales) pp. 159-185.

Barrientos Camus, Francisca (2012): "Las ventas atadas y la protección al consumidor. Comentarios críticos a la Nueva Regulación de la LPDC introducida por la Ley "Sernac Financiero", en Elorriaga, Fabián (coord.), Estudios de Derecho Civil VII, Jornadas Nacionales de Derecho Civil, Viña del Mar (Santiago, Universidad Adolfo Ibánez- AbeledoPerrot- Thomson Reuters) pp. 393- 408.

Barrientos Camus, Francisca (2011): "El vicio de la cosa comprada, la noción de vicio redhibitorio en el régimen de saneamiento del Código Civil y la ley sobre protección de los derechos de los consumidores", en De la Maza, Iñigo (coord.) Incumplimiento Contractual Nuevas Perspectivas, Cuadernos de Análisis Jurídico, Colección Derecho privado VII (Santiago, Ediciones Universidad Diego Portales) pp. 363-385.

Barrientos Camus, Francisca (2010): "La responsabilidad civil del fabricante bajo el artículo 23 de la Ley de Protección de los Derechos de los Consumidores y su relación con la responsabilidad civil del vendedor", Revista Chilena de Derecho Privado, N¹4: pp. 109-158.

Barrientos Zamorano, Marcelo (2008): Daños y deberes en las tratativas preliminares de un contrato (Santiago, LegalPublishing).

Barrientos Zamorano, Marcelo (2013): “Tendencias de la jurisprudencia reciente por daños en estacionamientos y el deber precontractual de seguridad en el consumo", en Domínguez, Carmen et al. (coord.), Estudios de Derecho Civil, Jornadas Nacionales de Derecho Civil, Santa Cruz 2012 (Santiago, LegalPublishing Thomson Reuters), pp. 429-437.

Barros Bourie, Enrique (2006): Tratado de Responsabilidad Extracontractual (Santiago, Editorial Jurídica de Chile).

Boetsch Gillet, Cristián (2011): La buena fe contractual (Santiago, Editorial Jurídica de Chile, Facultad de Derecho U. de Chile).

Bofill Genzsch, Jorge (1999): "Sanciones contravencionales y responsabilidad penal en el sistema de protección al consumidor", en Corral, Hernán (edit.), Derecho del Consumo y Protección al Consumidor, Cuadernos de Extensión Juridica 3 (Santiago, Universidad de los Andes, Facultad de Derecho) pp. 301-309.

Caprile Biermann, Bruno (2008): "Las acciones del comprador insatisfecho: el cúmulo actual (ley de protección al consumidor, vicios redhibitorios, error sustancial, resolución por incumplimiento), y la tendencia al deber de conformidad en el Derecho Comparado", en Mantilla, Fabricio y Pizarro (coor.), Estudios de Derecho Privado en homenaje a Christian Larroumet (Bogotá-Santiago de Chile) pp. 561-602. 
Carvajal Ramírez, Patricio-Ignacio (2011): "Tipicidad contractual y derecho de los consumidores Artículo 16, letra g) de la ley 19.496”, en Elorriaga, Fabián (coord.), Estudios de Derecho Civil VII, Jornadas Nacionales de Derecho civil, Viña del Mar (Santiago, Universidad Adolfo Ibánez- AbeledoPerrot- Thomson Reuters) pp. 441-448.

Corral Talciani, Hernán (2011): Responsabilidad por Productos Defectuosos, Análisis y Propuestas para El Derecho Civil y de Consumo en Chile (Santiago, Editorial AbeledoPerrotLegalPublishing).

Corral Talciani, Hernán (2006): "La responsabilidad por incumplimiento y por productos peligrosos en la ley de protección de los derechos de los consumidores”, en Baraona, Jorge y Lagos, Osvaldo (edit.), La Protección de los derechos de los consumidores en Chile, Cuadernos de Extensión Jurídica 12 (Santiago, Universidad de los Andes, Facultad de Derecho) pp. 95-110.

De la Maza Gazmuri, Iñigo (2010a): Los límites del deber precontracual de información (Madrid, Civitas Ediciones S.L.).

De la Maza Gazmuri, Iñigo (2010b): “Tipicidad y atipicidad de los deberes precontractuales de información" en Revista de Derecho de la Pontificia Universidad Católica de Valparaíso, Primer semestre 2010: pp. 75-99.

De la Maza Gazmuri, Iñigo (2009): "Ofertas sujetas a reserva: a propósito de los términos y condiciones en los contratos celebrados por medios electrónicos”, Revista de Derecho, Universidad Austral de Valdivia, vol. XXII, N² 2: pp. 75-95.

De la Maza Gazmuri, Iñigo (2008): "Buena fe, el reverso de la moneda. A propósito del dolo por omisión y el deber precontractual de informar", en Revista Chilena de Derecho Privado, diciembre de 2008 No 11: pp. 43-72.

Díez-Picazo, Luis (1996): Fundamentos del Derecho Civil Patrimonial, I, Introducción Teoría del Contrato (Madrid, Civitas, quinta edición).

Domínguez Hidalgo, Carmen (2000): El daño moral, tomos I y II (Santiago, Editorial Jurídica de Chile).

Fermandois Vöhringer, Arturo (2001): Derecho Constitucional Económico, Garantías Económicas, Doctrina y Jurisprudencia, El Orden Público Económico /La Libertad Económica/La No discriminación Arbitraria, tomo I (Santiago, Ediciones Universidad Católica de Chile).

Fermandois Vöhringer, Arturo (2010): Derecho Constitucional Económico, Regulación, Tributos y Propiedad, tomo II (Santiago, Ediciones UC).

Guerrero BéCAR, José Luis (2008): "La distinción entre contravención infraccional e incumplimiento contractual o contravención civil en materia de protección al consumidor”, en Guzmán, Alejandro (edit. científico) Colección de Estudios de Derecho Civil en Homenaje a la Profesora Inés Pardo de Carvallo (Valparaíso, Ediciones Universitarias de Valparaíso) pp. 433-453.

García Vicente, José Antonio (2009): “Título I Contrato con los Consumidores y Usuarios)", en Bercocovitz Rodríguez-Cano (coord.), Comentarios del texto Refundido de la Ley General para la defensa de los Consumidores y Usuarios y otras leyes complementarias (Aranzadi, Thomson-Reuters, Cizur) pp. 757-881.

Guzmán Brito, Alejandro (2002): "La buena fe en el Código Civil de Chile", en Revista Chilena de Derecho, vol 29 No 1, 2002: pp 11-23. 
Howells, Geraint y Schulze, Reiner (2009): “Overview of the Proposed Consumer Right Directive”, en Geraint Hoewlls y Reiner Schulze (edits.), Modernising and Harmonising Consumer Contract Law (Munich, European Law Publisher).

Hübner GuZmán, Ana María (1999): "Derecho a la contratación en la Ley de Protección al Consumidor”, en Corral, Hernán (edit.), Derecho del Consumo y Protección al Consumidor, Cuadernos de Extensión Jurídica 3 (Santiago, Universidad de los Andes, Facultad de Derecho) pp. 125-144.

Jara Amigo, Rony (1999): "Ámbito de aplicación de la ley chilena de protección al consumidor: inclusiones y exclusiones”, en Corral, Hernán (edit.), Derecho del Consumo y Protección al Consumidor, Cuadernos de Extensión Jurídica 3 (Santiago, Universidad de los Andes, Facultad de Derecho) pp. 47-74.

Larroumet, Christian (1998): Responsabilidad civil contractual, Algunos temas modernos (Santiago, Editorial Jurídica de Chile).

López Santa María, Jorge (2010): Los Contratos, Parte General (actual. por Fabián Elorrriaga De Bonis), (Santiago, Abeledo-Perrot-LegalPublishing, quinta edición).

Lorenzetti, Ricardo (2004): Tratado de los Contratos, Parte General, tomo I (Buenos Aires).

LorenzetTi, Ricardo (2002): "La oferta como apariencia y la aceptación basada en la confianza”, en Soto, Carlos y Vargas-Machuca, Roxana, (coord.), Contratación Privada, Contratos Predispuestos, Contratos Conexos, Código europeo de Contratos (Jurista Editores, Lima) pp. 35-72.

Lorenzini Barría, Jaime y Polit Corvalán, Joaquín (2013): "El régimen de la nulidad y la resolución en el derecho del consumidor chileno": en Domínguez, Carmen et al. (coord.), Estudio de Derecho Civil, Jornadas Nacionales de Derecho Civil, Santa Cruz 2012 (Santiago, LegalPublishing, Thomson-Reuters) pp. 465-480.

Micklitz, Hans; Reich, Norbert; RotT, Peter (2009): Understanding EU Consumer Law (Portland, Intersentia).

Miquel, José María (2002), "Capítulo II, No incorporación y Nulidad de determinadas condiciones generales", en Menéndez, Aurelio, y Díez-Picazo, Luis (directores), Comentarios a la Ley sobre Condiciones Generales de la Contratación (Madrid, Civitas).

Momberg Uribe, Rodrigo: (2013a): "La intervención judicial en el contrato a través del control de cláusulas abusivas", en Domínguez, Carmen et al. (coord.), Estudios de Derecho Civil, Jornadas Nacionales de Derecho Civil, Santa Cruz 2012 (Santiago, LegalPublishing, Thomson-Reuters) pp. 481-491.

Momberg Uribe, Rodrigo (2013b): "Artículo $1^{\circ} \mathrm{N}^{\circ} 1$. Definición consumidores y usuarios", en De la Maza, Iñigo y Pizarro, Pizarro (edits.) La Protección de los Derechos de los Consumidores, Comentarios a la Ley de Protección a los Derechos de los Consumidores (Santiago, Fundación Fernando Fueyo, UDP-Thomson Reuters) pp. 3-16.

Momberg Uribe, Rodrigo (2011): "La transformación de La ley de Protección de los Derechos de los Consumidores en la Norma Común del Derecho de Contratos Chileno", en Elorriaga, Fabián (coord.) Estudios de Derecho Civil VII, Jornadas de Derecho Civil, Viña del Mar 2011 (Santiago, Universidad Adolfo Ibáñez, AbeledoPerrot-Thomson) pp. 377391. 
Orlando, Salvatore (2011): "The Use of Unfair Contractual Terms as an Unfair Commercial Practice", en European Review of Contract Law, 2011, 1: pp. 25-56.

Pasquau Liaño, Miguel (1997): Nulidad y anulabilidad del contrato (Madrid, Civitas).

Nunes, Rizzatto (2011): Comentário ao Código Defesa do Consumidor (S. Paulo, Editora Saravia, $6^{a}$ edicao).

Pinochet Olave, Ruperto (2013): "Modificación unilateral de contrato y pacto de autorización: dos especies de cláusulas abusivas a la luz del derecho de consumo chileno. Comentario a la sentencia de la Exma. Corte de 24 de abril de 2013 recaída en 'Caso Sernac con Cencosud"”, en Ius et Praxis, Derecho en la Región, Año 19 No1: pp. 365-393.

Pinochet Olave, Ruperto (2011), "¿Integra el derecho del consumo el derecho Civil, el derecho Mercantil o conforma una disciplina jurídica autónoma?”, en Corral, Hernán et al. (coord.), Estudios de Derecho Civil, Parte General, Acto Jurídico y Derecho de Bienes, tomo I (Santiago, Abeledo-Perrot) pp. 51-62.

Pinochet Olave, Ruperto (2006): "Las reformas introducidas a la ley del consumidor por la ley 19.955 y especialmente el derecho de desistimiento en los contratos electrónicos", en Baraona, Jorge y Lagos, Osvaldo (edits.) La Protección de los derechos de los consumidores en Chile, Cuadernos de Extensión Jurídica 12 (Santiago, Universidad de los Andes, Facultad de Derecho) pp. 79-93.

Pizarro Wilson, Carlos (2012): "La eficacia del control de las cláusulas abusivas en el derecho chileno", en Barrientos Camus et al., Consumidores (Santiago, AbeledoPerrot, Thomson-Reuters) pp. 47-73.

Rodríguez Pinto, María Sara (2013): "Responsabilidad precontractual en la Ley $\mathrm{N}^{\circ}$ 19.496 de 1997 sobre Protección de los Derechos de los Consumidores", en Domínguez, Carmen et al. (coord.), Estudios de Derecho Civil, Jornadas Nacionales de Derecho Civil, Santa Cruz 2012 (Santiago, LegalPublishing, Thomson-Reuters) pp. 493-501.

Rodríguez Pinto, María Sara (2006): "Prestación de Servicios y Responsabilidad Civil en la Ley de Protección de los Derechos de los Consumidores", en Baraona, Jorge y Lagos, Osvaldo (edits.), La Protección de los derechos de los consumidores en Chile, Cuadernos de Extensión Jurídica 12 (Santiago, Universidad de los Andes, Facultad de Derecho) pp. 111-127.

Romero Seguel, Alejandro (1999): "Aspectos procesales de las acciones para la protección de los consumidores", en Corral, Hernán (edit.), Derecho del Consumo y Protección al Consumidor, Cuadernos de Extensión Jurídica 3 (Santiago, Universidad de los Andes, Facultad de Derecho) pp. 311-355.

SaAvedra Galleguillos, Francisco Javier (1994): Teoría del consentimiento (Santiago, Editorial Jurídica ConoSur).

Soto Coaguila, Carlos Alberto, (2004): "La contratación masiva y la crisis de la teoría clásica del contrato", en Mosset Iturraspe, Jorge y Soto Coaguila, Carlos Alberto (Trullijo, Editora Normas Legales).

Stiglitz, Rubén y STiglitz, Gabriel (1985): Contratos por adhesión, cláusulas abusivas y protección al consumidor (Buenos Aires, Depalma).

Tapia Rodríguez, Mauricio (2008): “Orden Público de Protección en el Derecho Chileno”, en Mantilla, Fabricio y Pizarro, Carlos (coords.) Estudios de Derecho Privado en ho- 
menaje a Christian Larroumet (Bogotá, Santiago de Chile, Fundación Fernando FueyoUniversidad Diego Portales y Universidad del Rosario) pp. 485-506.

Tapia Rodríguez, Mauricio y Valdivia Olivares, José Miguel (1999): Contratos por adhesión (Santiago, Editorial Jurídica de Chile).

Varas Braun, Andrés y Momberg Uribe, Rodrigo (2006): "La oferta en Chile: Un ordenamiento, tres Regímenes", en De la Maza, Iñigo (edit.) Temas de Contratos, Cuadernos de Análisis Jurídicos, Colección Derecho Privado III (Santiago, Ediciones Universidad Diego Portales, Escuela de Derecho) pp. 61-94.

Wahl Silva, Jorge (2006): "La protección de los derechos de los consumidores en Chile, Aspectos sustantivos y procesales luego de la reforma contenida en la Ley 19.955 de 2004", en Baraona, Jorge y Lagos, Osvaldo (edits.), La Protección de los derechos de los consumidores en Chile, Cuadernos de Extensión Jurídica 12 (Santiago, Universidad de los Andes, Facultad de Derecho) pp. 59-77.

Werner Pozo, Carmen y Nehme Zalaquet, Nicole (2005): "El rol de los conceptos de orden público, buenas costumbres y buena fe en la contratación entre partes desiguales", Martinic, María; Ríos, Sebastián; Tapia, Mauricio (edit.), Sesquicentenario del Código Civil de Andrés Bello, Pasado, presente y futuro de la Codificación, tomo I (Santiago, LexisNexis).

Zelaya Echegaray, Pedro (1999): "El cúmulo u opción de responsabilidades en la nueva ley de protección al consumidor”, en Corral, Hernán (edit.), Derecho del Consumo y Protección al Consumidor, Cuadernos de Extensión Jurídica 3 (Santiago, Universidad de los Andes, Facultad de Derecho) pp. 213-250.

Zuloaga Ríos, Isabel Margarita (2006): Teoría de la Responsabilidad Precontractual, Aplicaciones en la formación del consentimiento de los contratos (Santiago, LexisNexis,).

\section{SENTENCIAS CITADAS}

Sernac con Cencosud (2013): Corte Suprema de 24 de abril de 2013, Rol 12.355-11, CL/ JUR/880/2013.

Emiliano Arias Madariaga con SODIMAC S.A. (2007): Corte de Apelaciones de Concepción, 24 de diciembre de 2007, Rol 174-2005, CL/JUR/3107/2007.

Karina Andrea Sepúlveda Leiva; Fernando Augusto Sepúlveda Leiva con Fuchs y Compañia Limitada (2007): Corte de Apelaciones de Concepción, 8 de noviembre de 2007, Rol 500-2005, CL/JUR/5582/2007.

\section{NORMAS LEGALES CITADAS}

Constitución Política de la República: artículos: 1, 19 Nº 1 y 19 № 21.

Código Civil: artículos 12, 1445, 1545, 1560, 1556 a 1559 y 1683.

Código de Comercio: artículos 91 a 97.

LEY $N^{\circ} 19.496$ Normas sobre protección de los derechos de los consumidores, de 7 de marzo de 1997, Protección de los derechos de los consumidores, artículos $1 \mathrm{~N}^{\circ} 2,3$ a), 3 bis, 
b), c), 9, 12, 13, 14, 16, letra g), $17 \mathrm{~A}, 17 \mathrm{~B}, 17 \mathrm{C}, 17 \mathrm{D}, 17 \mathrm{G}, 17 \mathrm{~J}, 17 \mathrm{~L}, 20,21,23$ inciso segundo $31^{\circ}, 32,33,35,20,21,23$ inciso $2^{\circ}, 26,27,29,43,40,41,44$, y 50.

LEY N 19.955 , modifica la LEY N 19.496 sobre Protección de los derechos de los consumidores, de 29 de junio de 2004.

LEY N²0.416, fija Normas especiales para las empresas de menor tamaño, Diario Oficial 3 de febrero de 2010.

LEY N² 20.555, modifica LeY N 19.496, sobre Protección de los derechos de los consumidores, para dotar de atribuciones en materias financieras, entre otras, al Servicio Nacional del Consumidor, Diario Oficial de 5 de diciembre de 2011. 